\title{
Effects of Dexmedetomidine on motor- and somatosensory-evoked potentials in patients with thoracic spinal cord tumor: a randomized controlled trial
}

\author{
Yan Li', Lingzhong Meng ${ }^{3}$, Yuming Peng ${ }^{1}$, Hui Qiao ${ }^{2}$, Lanjun Guo ${ }^{4}$, Ruquan Han ${ }^{1 *}$ and Adrian W. Gelb ${ }^{3}$
}

\begin{abstract}
Background: We hypothesized that the addition of dexmedetomidine in a clinically relevant dose to propofolremifentanil anesthesia regimen does not exert an adverse effect on motor-evoked potentials (MEP) and somatosensory-evoked potentials (SSEP) in adult patients undergoing thoracic spinal cord tumor resection.

Methods: Seventy-one adult patients were randomized into three groups. Propofol group $(n=25)$ : propofolremifentanil regimenand the dosage was adjusted to maintain the bispectral index (BIS) between 40 and 50 . DP adjusted group ( $n=23)$ : Dexmedetomidine $(0.5 \mu \mathrm{g} / \mathrm{kg}$ loading dose infused over $10 \mathrm{~min}$ followed by a constant infusion of $0.5 \mathrm{\mu g} / \mathrm{kg} / \mathrm{h}$ ) was added to the propofol-remifentanil regimen and propofol was adjusted to maintain BIS between 40 and 50. DP unadjusted group ( $n=23)$ : Dexmedetomidine (administer as DP adjusted group) was added to the propofol-remifentanil regimen and propofol was not adjusted. All patients received MEP, SSEP and BIS monitoring.
\end{abstract}

Results: There were no significant changes in the amplitude and latency of MEP and SSEP among different groups $(P>0.05)$. The estimated propofol plasma concentration in DP adjusted group $(2.7 \pm 0.3 \mu \mathrm{g} / \mathrm{ml})$ was significantly lower than in propofol group $(3.1 \pm 0.2 \mu \mathrm{g} / \mathrm{ml})$ and DP unadjusted group $(3.1 \pm 0.2 \mu \mathrm{g} / \mathrm{ml})(P=0.000)$. BIS in DP unadjusted group (35 \pm 5 ) was significantly lower than in propofol group (44 \pm 3$)(P=0.000)$.

Conclusions: The addition of dexmedetomidine to propofol-remifentanil regimen does not exert an adverse effect on MEP and SSEP monitoring in adult patients undergoing thoracic spinal cord tumor resection.

Trial registration: The study was registered with the Chinese Clinical Trial Registry on January 31st, 2014. The reference number was ChiCTR-TRC-14004229.

Keywords: Motor-evoked potentials, Somatosensory-evoked potentials, Dexmedetomidine, RCT, Spinal cord tumor

\section{Background}

Motor-evoked potential (MEP) and somatosensory-evoked potential (SSEP) monitoring are widely used during spinal surgeries, which threat the integrity of motor and sensory pathways in the spinal cord. The effect of anesthetic agents on the amplitude and latency of MEP and SSEP monitoring is dose-dependent [1-3]. Total intravenous anesthesia (TIVA) with propofol and opioid

\footnotetext{
* Correspondence: ruquan.han@gmail.com

'Department of Anesthesiology, Beijing Tiantan Hospital, Capital Medical University, No. 6 Tiantan Xili Dongcheng District, Beijing, China 100050

Full list of author information is available at the end of the article
}

is commonly recommended for surgeries that require MEP and SSEP monitoring [1, 4]. However, even propofol used with a large dose can also affect MEP monitoring [5].

Dexmedetomidine is a potent and highly selective alpha-2 agonist. It has the effect of sedation, analgesia, sympatholysis, minimal respiratory depression and possible neuroprotection [6-9]. Its addition to the anesthetic regimen is believed to have the potential of sparing other hypnotics requirement, especially propofol, thus facilitating MEP and SSEP monitoring while providing the beneficial effects it has. Previous studies 
examining the effect of dexmedetomidine on MEP and SSEP monitoring claimed both a null $[4,10-14]$ and significant adverse effect $[11,15]$. The design of most studies was longitudinal in which patients served as their own controls [10-13]. Therefore, the results may be confounded by the carryover or top-up effect after the addition of dexmedetomidine. The only randomized controlled trial used etomidate instead of propofol for anesthetic maintenance and this is not a currently recommended practice [4].

Another consideration is that all the previous studies were done in patients suffering from various non-tumor spinal conditions. In patients diagnosed with spinal cord tumor, the combination of dexmedetomidine may affect MEP and SSEP monitoring differently compared with surgery on the bony structures only because the neural pathways may have been adversely injured by the tumor $[16,17]$.

In this study we propose our hypothesis that the combination of dexmedetomidine in a clinically relevant dose to an anesthetic regimen reduces propofol and remifentanil requirement does not exert an adverse effect on MEP and SSEP monitoring in patients with thoracic spinal cord tumors.

\section{Methods}

This single-center and randomized study was conducted in Beijing Tiantan Hospital, Capital Medical University. The study was approved by the Ethics Committee of Beijing Tiantan Hospital, Capital Medical University (reference number was ky-2010-018-02). Written informed consent was obtained from all participants. The study was registered with the Chinese Clinical Trial Registry (the reference number was ChiCTR-TRC14004229).

\section{Patients}

We recruited patients scheduled for elective thoracic spinal cord tumor resection based on magnetic resonance imaging (MRI) studies. Other inclusion criteria included age between 18 and 60 years old and American Society of Anesthesiologists (ASA) physical status I or II. The patients who were pregnant and/or lactating, chronic using or addiction of analgesics were excluded from the study. The patients who were with illegal drug or alcohol abuse, obesity $\left(B M I \geq 30 \mathrm{~kg} / \mathrm{m}^{2}\right)$, anemia (hemoglobin $<11 \mathrm{~g} / \mathrm{dl}$ ), and major organ dysfunctions were also excluded from the study.

\section{Grouping}

Patients who met the recruitment criteria were randomly assigned to one of the three study groups, labeled "propofol group", "DP adjusted group", or "DP unadjusted group". Randomization was based on a computer generated random digits table (SPSS Inc., Chicago, IL). Permuted-block randomization was used with a block size of 3 and an allocation ratio of 1:1:1. Since anesthesiologist was in charge of the anesthesia management and all evaluation of outcomes were based on the result of electrophysiological monitoring, the anesthesiologist could not be blinded. Neurophysiologists and patients were blinded to the study group till the evaluation finished. In propofol group, the anesthesia was maintained using propofol and remifentanil infusions only. The blood plasma concentration of remifentanil was fixed at $4 \mathrm{ng} / \mathrm{ml}$ while the propofol infusion was adjusted to maintain the BIS measurement between 40 and 50. In DP adjusted group, dexmedetomidine $(0.5 \mu \mathrm{g} / \mathrm{kg}$ loading dose infused over $10 \mathrm{~min}$ followed by a constant infusion rate of $0.5 \mu \mathrm{g} / \mathrm{kg} / \mathrm{h}$ ) was added to propofol and remifentanil infusions. While the dexmedetomidine infusion was standardized and the blood plasma concentration of remifentanil was fixed at $4 \mathrm{ng} / \mathrm{ml}$ while the propofol infusion was adjusted to maintain the BIS measurement between 40 and 50 for $90 \%$ of anesthesia time and no deviations for more than $5 \mathrm{~min}$. In DP unadjusted group, the anesthesia was maintained using propofol and remifentanil infusions as in propofol group. After BIS was maintained between 40 and 50, dexmedetomidine was then added $(0.5 \mu \mathrm{g} / \mathrm{kg}$ loading dose infused over $10 \mathrm{~min}$ followed by a constant infusion rate of $0.5 \mu \mathrm{g} / \mathrm{kg} / \mathrm{h}$ ). The propofol was not adjusted as in DP unadjusted group.

\section{Anesthesia and management}

The patients did not receive premedication. Anesthesia was induced by propofol $(5 \mu \mathrm{g} / \mathrm{ml})$ infusion managed with a Diprifusor propofol infusion device (Marsh model, Master Target Control infusion system, Fresenius-Vial, Brezins, France), remifentanil ( $4 \mathrm{ng} / \mathrm{ml})$ infusion managed with an infusion device (Minto model CP-600TCI, Beijing Slgo Medical Technology Co., Ltd., Beijing, China) and rocuronium $(0.6 \mathrm{mg} / \mathrm{kg})$. Then patients received endotracheal intubation and mechanical ventilation adjusting to maintain the end-tidal carbon dioxide between 35 and $40 \mathrm{mmHg}$. In addition to the routine ASA monitors, patients received MEP (Cascade, Cadwell Laboratories Inc, WA, USA), SSEP (Cascade, Cadwell Laboratories Inc, WA, USA), bispectral index (BIS) (BIS ${ }^{\mathrm{m}}$, Covidien, San Jose, CA, USA) and intra-arterial blood pressure monitoring. Bradycardia, defined as the heart rate $(H R)<50 \mathrm{bpm}$, was treated with atropine $(0.5 \mathrm{mg})$ bolus administration. Hypotension, defined as a decreasing of mean arterial pressure (MAP) more than twenty percentage of the baseline, was treated by using a dopamine infusion titrated. The baseline blood pressure value was determined based on preoperative evaluation on the day before surgery. 


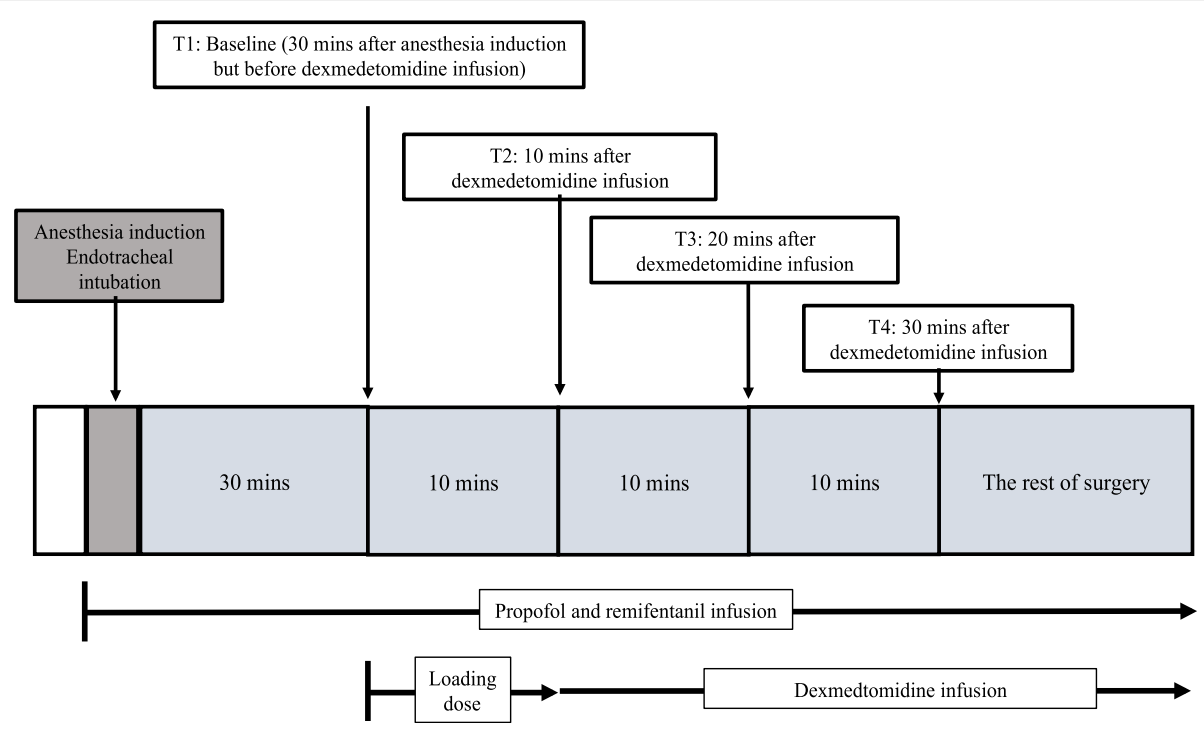

Fig. 1 Flow chart of study protocol

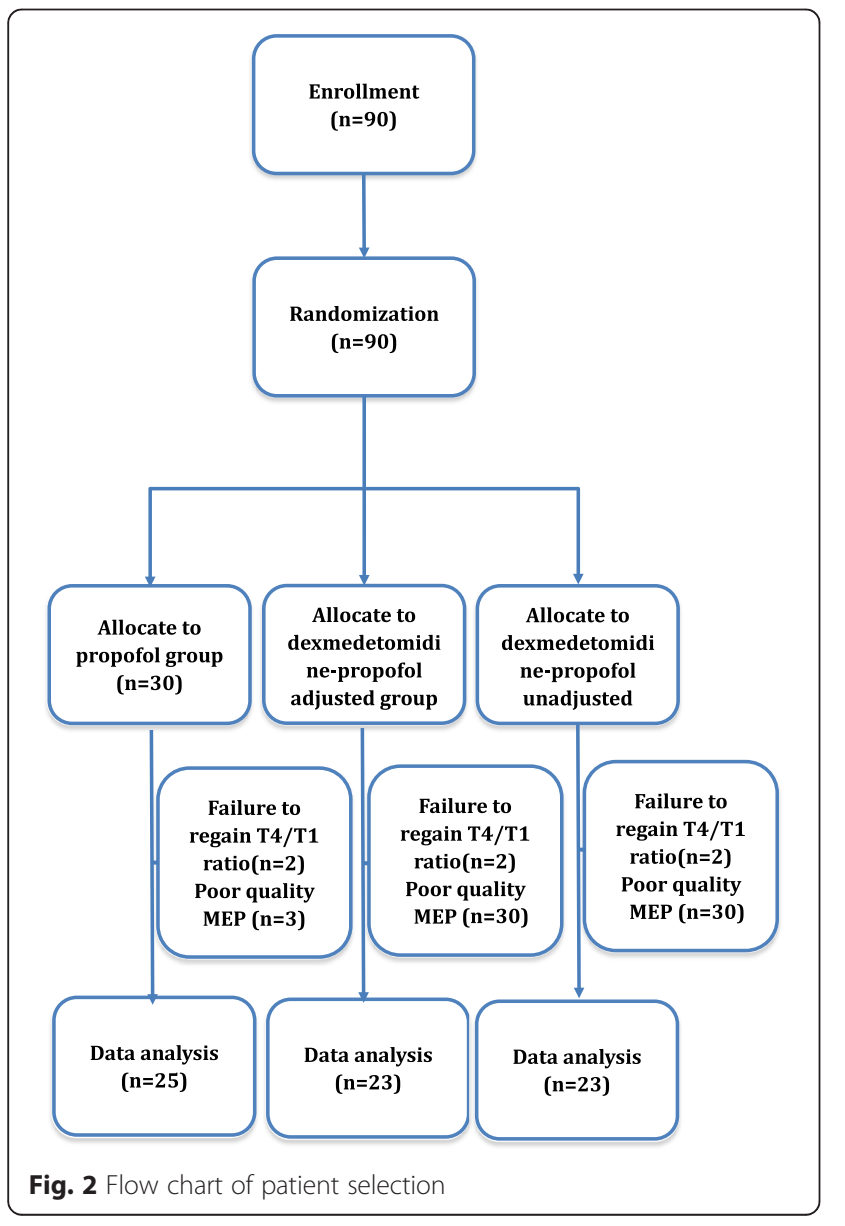

Motor- and somatosensory-evoked potential monitoring MEP was recorded from paired needle electrodes placed bilaterally in the tibias anterior and extensor digital muscles, and hand muscles. Electrical current delivered to corkscrew electrodes were inserted at the C3 and C4 sites (international 10-20 system) with train of six to nine pulses, 300 to 500 volts, $75 \mathrm{~ms}$ interval pause (ISI) and one to four microsecond of inter-stimulus interval using Cadwell Cascade neurophysiologic monitoring system (Cascade, Cadwell Laboratories Inc, WA, USA). Anodal stimulation was applied to trigger contralateral MEP responses. The number of pulses and voltage were established at baseline and maintained throughout the surgery. Surfacestimulating electrodes for SSEP monitoring were placed over each ulnar nerve at the wrists and over each posterior tibial nerve at the ankles. Needle electrodes were placed over the somatosensory hand cortex at scalp sites $\mathrm{C} 3{ }^{\prime}-\mathrm{Fz}$, $\mathrm{C}^{\prime}{ }^{\prime}-\mathrm{Fz}, \mathrm{Cz}^{\prime}-\mathrm{Fz}$ and $\mathrm{C}^{\prime}{ }^{\prime}-\mathrm{C}^{\prime}$ ' to record the primary cortical responses. Ulnar and posterior tibial nerves were stimulated synchronously at $2.79 / \mathrm{s}$ and averaged over 500 stimuli. Ulnar nerves were stimulated at $15 \mathrm{~mA}$, and posterior tibial nerves were stimulated at $25 \mathrm{~mA}$. Then europhysiologists were blinded to the group till the evaluation finished.

Table 1 Demographic data (mean \pm SD)

\begin{tabular}{lllll}
\hline Group & $\begin{array}{l}\text { Sex } \\
\text { (male/female) }\end{array}$ & $\begin{array}{l}\text { Age } \\
\text { (year) }\end{array}$ & $\begin{array}{l}\text { Height } \\
(\mathrm{cm})\end{array}$ & $\begin{array}{l}\text { Weight } \\
(\mathrm{kg})\end{array}$ \\
\hline Propofol group $(n=25)$ & $18 / 7$ & $40 \pm 11$ & $169 \pm 7$ & $68 \pm 11$ \\
$\begin{array}{l}\text { DP adjusted group } \\
(n=23)\end{array}$ & $12 / 11$ & $40 \pm 14$ & $164 \pm 7$ & $65 \pm 10$ \\
$\begin{array}{l}\text { DP unadjusted group } \\
(n=23)\end{array}$ & $13 / 10$ & $41 \pm 13$ & $166 \pm 9$ & $63 \pm 13$ \\
\hline
\end{tabular}


Table 2 Muscle strength of the lower extremities before surgery (mean $\pm \mathrm{SD}$ )

\begin{tabular}{lllll}
\hline Group & Left & $P$ & Right & P \\
\hline Propofol group $(n=25)$ & $4.3 \pm 1.0$ & & $4.2 \pm 1.0$ & \\
DP adjusted group $(n=23)$ & $4.1 \pm 1.1$ & 0.72 & $4.1 \pm 1.1$ & 0.82 \\
DP unadjusted group $(n=23)$ & $4.2 \pm 1.1$ & 0.83 & $4.3 \pm 1.1$ & 0.74 \\
\hline P: Compan
\end{tabular}

P: Comparison with propofol group

Prior to surgery, the muscle strength of the left and right lower extremity was assessed by the attending neurosurgeon who was blinded to the randomization using a 0-2-5 scale, with 5 indicating normal strength and 0 complete paralysis. MEP, SSEP, BIS, mean arterial pressure (MAP) and heart rate (HR) were measured at 4 different time points (Fig. 1). T1 was the baseline value obtained $30 \mathrm{~min}$ after anesthesia induction and endotracheal intubation but before the dexmedetomidine infusion. T2 was $10 \mathrm{~min}$ after T1 when the dexmedetomidine loading dose infusion $(0.5 \mu \mathrm{g} / \mathrm{kg}$ over $10 \mathrm{~min})$ was just finished in DP adjusted group and DP unadjusted group. All variables were recorded again when the dexmedetomidine maintenance infusion $(0.5 \mu \mathrm{g} / \mathrm{kg} / \mathrm{h})$ has lasted for 10 (T3) and 20 (T4) minutes, respectively, in both groups. The muscle relaxation related to rocuronium was reversed using neostigmine $(0.05-0.07 \mathrm{mg} / \mathrm{kg})$ if necessary before the first measurement. A T4/T1 $90 \%$ recovery of the muscle strength based on the train-of-four ratio was deemed acceptable for the study. All measurements were done with the patient in the lateral position and prior to skin incision in order to avoid the confounding effect of surgical manipulation on MEP and SSEP monitoring. More than $50 \%$ decrease of the amplitude and more than $10 \%$ prolongation of the latency of both SSEP and MEP monitoring from the baseline values were defined as clinically meaningful changes [18].

\section{Statistical analysis}

Sample size calculation was performed by PASS 2008 software (NCSS LLC, USA) for windows. Based on the study in which used MEP amplitude $(500 \mu \mathrm{V}$; SD,110) to detect a $50 \%$ difference in MEP amplitude (decrease from 500 to $250 \mu \mathrm{V}$ ) [13], 20 patients were required to detect an effect size of 0.8 , assuming a power of $80 \%$ and a 2 -sided $\alpha$ level of $5 \%$. Considering the possibility of early termination during the study and $20-30 \%$ for a drop-out rate, therefore 30 patients were recruited in each group.

Statistical analyses were performed using the Statistical Package for Social Sciences (Version 19.0, SPSS Inc., Chicago, IL). All quantitative data were analyzed for normal distribution and homogeneity of variance. Data that showed a normal distribution were presented as the means $\pm \mathrm{SD}$. The non-normal distribution data were presented as median. One-way analysis of variance (ANOVA) of repeated measurements was used to evaluate differences between the means at different time points in one group. Variables between groups underwent StudentNewman-Keuls tests with multiple comparison correction. All $P$ values were two sided, and $\alpha$ level of 0.05 was considered statistically significant.

\section{Results}

Ninety patients were equally enrolled in this study. 19 patients were excluded from analysis due to either poor quality MEP monitoring (3, 5, 5 in 3 groups respectively) or failure to regain T4 ratio which defined as T4/ T1 recovered less than $90 \%$ based on the train-of-four ratio after the intubation ( 2 in each group). The patients' recruitment was showed in Fig. 2. There were no significant differences of age, gender, height, and weight among groups (Table 1). There were no significant differences in the muscle strength of the left and right lower extremities among different groups (Table 2).

The estimated blood plasma concentration of propofol in DP adjusted group $(2.7 \pm 0.3 \mu \mathrm{g} / \mathrm{ml})$ was significantly lower than in propofol group and DP unadjusted group $(3.1 \pm 0.2 \mu \mathrm{g} / \mathrm{ml}$ and $3.1 \pm 0.2 \mu \mathrm{g} / \mathrm{ml})(P=0.000)$ (Table 3).

There were no significant differences in MAP and HR among different measurement points in propofol group (Table 4). In DP adjusted group (93 $\pm 14 \mathrm{mmHg}$ ) and DP unadjusted group $(94 \pm 10 \mathrm{mmHg}$ ) the MAP was significantly higher than propofol group $(86 \pm 15 \mathrm{mmHg})(P=$ $0.037,0.032)$. In DP unadjusted group, the HR at T2-T4 $(59 \pm 6,59 \pm 5,60 \pm 6 \mathrm{pbm})$ was lower than $\mathrm{T} 1(66 \pm 8 \mathrm{pbm})$ ( $P=0.000,0.000,0.003$, respectively).

There were no significant differences in the BIS of propofol groups and DP adjusted group (Table 4). However, the BIS measured at points T2-T4 in DP unadjusted group (37 $\pm 6,35 \pm 5,35 \pm 6$ ) was lowered than the corresponding points in propofol group $(44 \pm 3,44 \pm 3,42 \pm 8)(P=0.000)$.

Table 3 Estimated plasma concentration of propofol $(\mu \mathrm{g} / \mathrm{ml}$, mean $\pm \mathrm{SD})$ at different time points

\begin{tabular}{|c|c|c|c|c|c|c|c|c|}
\hline Group & $\mathrm{T} 1(\mu \mathrm{g} / \mathrm{ml})$ & $P$ & $\mathrm{~T} 2(\mu \mathrm{g} / \mathrm{ml})$ & $P$ & $\mathrm{~T} 3(\mu \mathrm{g} / \mathrm{ml})$ & $P$ & $\mathrm{~T} 4(\mu \mathrm{g} / \mathrm{ml})$ & $P$ \\
\hline Propofol group $(n=25)$ & $3.1 \pm 0.2$ & & $3.1 \pm 0.2$ & & $3.1 \pm 0.2$ & & $3.1 \pm 0.2$ & \\
\hline DP adjusted group $(n=23)$ & $3.0 \pm 0.2$ & 0.313 & $2.8 \pm 0.2^{a}$ & 0.003 & $2.7 \pm 0.3^{* a}$ & 0.000 & $2.7 \pm 0.3^{* a}$ & 0.000 \\
\hline DP unadjusted group $(n=23)$ & $3.1 \pm 0.2$ & 0.829 & $3.1 \pm 0.2$ & 0.829 & $3.1 \pm 0.2$ & 0.939 & $3.1 \pm 0.2$ & 0.939 \\
\hline
\end{tabular}

* $P=0.01$ (comparison among different time points)

${ }^{\mathrm{a} C o m p a r i s o n}$ with propofol group 
Table 4 MAP, HR, BIS at different time points (mean \pm SD)

\begin{tabular}{|c|c|c|c|c|c|c|c|c|c|}
\hline Variable & Group & $\mathrm{T1}$ & $P$ & $\mathrm{~T} 2$ & $P$ & T3 & $P$ & T4 & $P$ \\
\hline \multirow[t]{3}{*}{$\mathrm{MAP}(\mathrm{mmHg})$} & Propofol group $(n=25)$ & $86 \pm 11$ & & $86 \pm 15$ & & $86 \pm 13$ & & $84 \pm 12$ & \\
\hline & DP adjusted group $(n=23)$ & $80 \pm 11$ & 0.061 & $93 \pm 14^{* * a}$ & 0.037 & $95 \pm 15^{* * a}$ & 0.019 & $95 \pm 12^{* * a}$ & 0.003 \\
\hline & DP unadjusted group $(n=23)$ & $80 \pm 10$ & 0.098 & $94 \pm 10^{* * a}$ & 0.032 & $95 \pm 13^{* * a}$ & 0.019 & $95 \pm 11^{* * a}$ & 0.003 \\
\hline \multirow[t]{3}{*}{$\mathrm{HR}(\mathrm{bpm})$} & Propofol group $(n=25)$ & $65 \pm 10$ & & $60 \pm 7$ & & $59 \pm 6$ & & $60 \pm 8$ & \\
\hline & DP adjusted group $(n=23)$ & $64 \pm 10$ & 0.541 & $59 \pm 9$ & 0.464 & $58 \pm 9^{*}$ & 0.816 & $59 \pm 8$ & 0.626 \\
\hline & DP unadjusted group $(n=23)$ & $66 \pm 8$ & 0.841 & $59 \pm 6^{* *}$ & 0.489 & $59 \pm 5^{* *}$ & 0.842 & $60 \pm 6^{*}$ & 0.850 \\
\hline \multirow[t]{3}{*}{ BIS } & Propofol group $(n=25)$ & $45 \pm 3$ & & $44 \pm 3$ & & $44 \pm 3$ & & $42 \pm 8$ & \\
\hline & DP adjusted group $(n=23)$ & $44 \pm 4$ & 0.393 & $43 \pm 3$ & 0.146 & $43 \pm 3$ & 0.428 & $43 \pm 3$ & 0.534 \\
\hline & DP unadjusted group $(n=23)$ & $45 \pm 3$ & 0.732 & $37 \pm 6^{* * a}$ & 0.000 & $35 \pm 5^{* * a}$ & 0.000 & $35 \pm 6^{* * a}$ & 0.000 \\
\hline
\end{tabular}

${ }^{*} P<0.05,{ }^{* *} P=0.000$ (comparison among different time points)

${ }^{\text {a } C o m p a r i s o n ~ w i t h ~ p r o p o f o l ~ g r o u p ~}$

There were no significant changes in the amplitude and latency of both MEP (Table 5) and SSEP (Table 6) among different time pointsin all 3 groups $(P>0.05)$. There were also no significant differences of the measurements among different groups $(P>0.05)$.

\section{Discussion}

This randomized controlled study in patients with thoracic spinal cord tumors shows that the addition of dexmedetomidine to a TIVA regimen comprising of propofol and remifentanil does not adversely affect the

Table 5 Motor-evoked potential at different time points (mean \pm SD)

\begin{tabular}{|c|c|c|c|c|c|}
\hline Group & Measurement & $\mathrm{T} 1$ & $\mathrm{~T} 2$ & $\mathrm{~T} 3$ & $\mathrm{~T} 4$ \\
\hline \multirow[t]{8}{*}{ Propofol group $(n=25)$} & ULA (uv) & $280 \pm 148$ & $307 \pm 147$ & $326 \pm 154$ & $326 \pm 169$ \\
\hline & ULL (ms) & $20.7 \pm 3.2$ & $21.3 \pm 2.2$ & $21.6 \pm 2.4$ & $21.9 \pm 2.3$ \\
\hline & URA (uv) & $323 \pm 139$ & $307 \pm 138$ & $366 \pm 164$ & $343 \pm 145$ \\
\hline & URL (ms) & $21.2 \pm 3.6$ & $22.2 \pm 4.0$ & $21.8 \pm 2.7$ & $21.6 \pm 3.5$ \\
\hline & LLA (uv) & $152 \pm 84$ & $177 \pm 82$ & $208 \pm 141$ & $221 \pm 113$ \\
\hline & LLL (ms) & $38.9 \pm 4.8$ & $40.1 \pm 5.7$ & $40.2 \pm 6.9$ & $39.4 \pm 6.6$ \\
\hline & LRA (uv) & $127 \pm 91$ & $121 \pm 84$ & $140 \pm 90$ & $131 \pm 105$ \\
\hline & LRL (ms) & $39.0 \pm 9.9$ & $39.4 \pm 10.6$ & $40.4 \pm 11.1$ & $39.6 \pm 4.2$ \\
\hline \multirow[t]{8}{*}{ DP adjusted group $(n=23)$} & ULA (uv) & $293 \pm 131$ & $341 \pm 207$ & $313 \pm 155$ & $313 \pm 178$ \\
\hline & ULL (ms) & $20.8 \pm 2.1$ & $21.8 \pm 3.6$ & $21.3 \pm 3.6$ & $20.9 \pm 2.8$ \\
\hline & URA (uv) & $256 \pm 137$ & $302 \pm 193$ & $303 \pm 158$ & $339 \pm 206$ \\
\hline & URL (ms) & $21.1 \pm 2.6$ & $20.6 \pm 2.8$ & $20.9 \pm 3.0$ & $21.5 \pm 3.3$ \\
\hline & LLA (uv) & $174 \pm 135$ & $185 \pm 129$ & $179 \pm 106$ & $153 \pm 78$ \\
\hline & LLL (ms) & $39.4 \pm 5.2$ & $39.5 \pm 3.6$ & $39.2 \pm 3.2$ & $37.3 \pm 9.9$ \\
\hline & LRA (uv) & $154 \pm 77$ & $173 \pm 153$ & $187 \pm 137$ & $160 \pm 98$ \\
\hline & LRL (ms) & $40.5 \pm 3.9$ & $40.6 \pm 4.1$ & $40.8 \pm 5.0$ & $41.3 \pm 5.3$ \\
\hline \multirow[t]{8}{*}{ DP unadjusted group $(n=23)$} & ULA (uv) & $354 \pm 179$ & $353 \pm 116$ & $343 \pm 153$ & $355 \pm 158$ \\
\hline & ULL (ms) & $21.4 \pm 2.3$ & $21.3 \pm 2.4$ & $22.1 \pm 4.0$ & $23.1 \pm 3.8$ \\
\hline & URA (uv) & $354 \pm 161$ & $351 \pm 191$ & $316 \pm 197$ & $292 \pm 163$ \\
\hline & URL (ms) & $21.6 \pm 2.6$ & $21.7 \pm 3.0$ & $22.4 \pm 4.0$ & $23.1 \pm 4.1$ \\
\hline & LLA (uv) & $171 \pm 114$ & $196 \pm 171$ & $215 \pm 178$ & $169 \pm 144$ \\
\hline & LLL (ms) & $41.2 \pm 4.4$ & $40.0 \pm 4.2$ & $39.8 \pm 3.5$ & $39.9 \pm 3.6$ \\
\hline & LRA (uv) & $206 \pm 153$ & $207 \pm 192$ & $225 \pm 177$ & $199 \pm 138$ \\
\hline & LRL (ms) & $38.4 \pm 10.7$ & $39.8 \pm 4.2$ & $40.7 \pm 4.7$ & $38.2 \pm 10.0$ \\
\hline
\end{tabular}

ULA amplitude of left upper limb, ULL latency of left upper limb, URA amplitude of right upper limb, URL latency of right upper limb, LLA amplitude of left lower limb, LLL latency of left lower limb, LRA amplitude of right lower limb, LRL latency of right lower limb P: Comparison with propofol group 
Table 6 Somatosensory-evoked potential at different time points (mean \pm SD)

\begin{tabular}{|c|c|c|c|c|c|}
\hline Group & Measurement & T1 & $\mathrm{T} 2$ & T3 & T4 \\
\hline \multirow[t]{8}{*}{ Propofol group $(n=25)$} & ULA (uv) & $2.0 \pm 0.9$ & $1.9 \pm 0.7$ & $1.8 \pm 0.9$ & $2.1 \pm 1.0$ \\
\hline & ULL (ms) & $20.1 \pm 0.8$ & $20.3 \pm 1.2$ & $20.5 \pm 1.4$ & $20.6 \pm 1.5$ \\
\hline & URA (uv) & $2.4 \pm 1.4$ & $2.1 \pm 1.1$ & $2.3 \pm 1.3$ & $1.9 \pm 1.1$ \\
\hline & URL (ms) & $20.2 \pm 1.4$ & $20.2 \pm 1.3$ & $20.5 \pm 1.3$ & $20.6 \pm 1.6$ \\
\hline & LLA(uv) & $1.1 \pm 1.1$ & $1.0 \pm 0.9$ & $1.1 \pm 0.8$ & $1.1 \pm 0.9$ \\
\hline & LLL (ms) & $39.6 \pm 4.0$ & $40.1 \pm 4.2$ & $40.2 \pm 4.3$ & $39.8 \pm 4.6$ \\
\hline & LRA(uv) & $1.3 \pm 1.2$ & $1.6 \pm 2.2$ & $1.0 \pm 1.0$ & $0.8 \pm 0.9$ \\
\hline & LRL (ms) & $40.8 \pm 4.6$ & $40.7 \pm 4.5$ & $40.9 \pm 4.5$ & $40.7 \pm 4.7$ \\
\hline \multirow[t]{8}{*}{ DP adjusted group $(n=23)$} & ULA (uv) & $2.0 \pm 1.1$ & $2.1 \pm 1.1$ & $2.0 \pm 1.1$ & $2.0 \pm 1.1$ \\
\hline & ULL (ms) & $19.2 \pm 1.5$ & $19.4 \pm 1.6$ & $19.7 \pm 1.6$ & $19.7 \pm 1.7$ \\
\hline & URA (uv) & $2.1 \pm 1.4$ & $2.1 \pm 1.3$ & $2.3 \pm 1.2$ & $2.3 \pm 1.3$ \\
\hline & URL (ms) & $19.8 \pm 1.8$ & $19.8 \pm 1.5$ & $20.0 \pm 1.5$ & $19.9 \pm 1.5$ \\
\hline & LLA(uv) & $1.5 \pm 1.5$ & $1.5 \pm 1.6$ & $1.8 \pm 2.0$ & $1.5 \pm 1.2$ \\
\hline & LLL(ms) & $39.7 \pm 4.4$ & $40.4 \pm 4.1$ & $40.9 \pm 4.8$ & $41.2 \pm 4.1$ \\
\hline & LRA(uv) & $1.4 \pm 1.6$ & $1.6 \pm 1.8$ & $1.6 \pm 2.0$ & $1.5 \pm 1.8$ \\
\hline & LRL (ms) & $38.8 \pm 3.8$ & $40.0 \pm 3.3$ & $40.1 \pm 3.2$ & $39.6 \pm 2.4$ \\
\hline \multirow[t]{8}{*}{ DP unadjusted group $(n=23)$} & ULA (uv) & $1.6 \pm 1.0$ & $1.7 \pm 1.0$ & $1.7 \pm 1.1$ & $1.8 \pm 1.1$ \\
\hline & ULL (ms) & $19.2 \pm 2.1$ & $19.4 \pm 2.2$ & $19.6 \pm 2.4$ & $19.2 \pm 3.1$ \\
\hline & URA(uv) & $1.6 \pm 1.0$ & $1.7 \pm 0.9$ & $1.5 \pm 0.9$ & $1.6 \pm 0.8$ \\
\hline & URL(ms) & $19.8 \pm 2.7$ & $20.1 \pm 2.6$ & $20.3 \pm 2.3$ & $20.1 \pm 2.7$ \\
\hline & LLA(uv) & $1.1 \pm 1.0$ & $0.9 \pm 0.7$ & $1.2 \pm 1.0$ & $1.3 \pm 1.0$ \\
\hline & LLL(ms) & $39.8 \pm 4.3$ & $39.9 \pm 3.9$ & $40.6 \pm 4.1$ & $41.0 \pm 4.3$ \\
\hline & LRA(uv) & $1.0 \pm 0.7$ & $0.7 \pm 0.4$ & $1.1 \pm 0.7$ & $1.3 \pm 1.0$ \\
\hline & LRL (ms) & $39.8 \pm 4.1$ & $40.2 \pm 4.1$ & $41.3 \pm 4.5$ & $41.1 \pm 4.3$ \\
\hline
\end{tabular}

ULA amplitude of left upper limb, ULL latency of left upper limb, URA amplitude of right upper limb, URL latency of right upper limb, LLA amplitude of left lower limb, LLL latency of left lower limb, LRA amplitude of right lower limb, LRL latency of right lower limb

P: comparison with propofol group

MEP and SSEP monitoring, and the addition of dexmedetomidine reduces the propofol requirements for a comparable BIS measurement. Moreover, the deepening of anesthesia via propofol infusion does not necessarily affect the MEP and SSEP monitoring.

All major hypnotic agents used in anesthesia can exert dose-dependent adverse effect on MEP and SSEP monitoring [1-3]. Inhalational anesthetic agents have a potent effect and therefore are either avoided or used in low concentrations during MEP monitoring [1-4]. Propofol at higher concentrations can also depress the amplitude of the MEP [5]. Currently, the anesthetic technique that is frequently recommended during MEP and SSEP monitoring is a TIVA regimen comprising of multiple drugs at lower doses than usually used. The rationale of this strategy is to provide an adequate and balanced anesthesia via a combination of drugs that have different but supplementary mechanisms while minimizing the adverse effect on evoked potential monitoring of an otherwise large dose if the drug is used alone. This strategy is typically executed via a propofol-opioid, either remifentanil or fentanyl, combination $[1,4]$.

The multiple advantageous properties of dexmedetomidine make it a potentially useful drug for inclusion in a TIVA regimen in monitored cases [11-14]. The rationale for adding dexmedetomidine is to reduce the dose of propofol or to deepen the anesthesia without increasing the propofol infusion rate, in addition to potentiation of the opioid analgesia [11-14]. Previous studies suggested that the effect of dexmedetomidine on MEP and SSEP monitoring is dose-dependent with the drug blood concentration of $0.3-0.6 \mathrm{ng} / \mathrm{ml}$ producing no adverse effect [10] while that of $0.6-0.8 \mathrm{ng} / \mathrm{ml}$ causing a significant attenuation of the MEP amplitude [11]. However, these results are difficult to consolidate because one study used propofol-remifentanil [12] while the other desfluraneremifentanil [10]. Moreover, the designs of these studies were heterogeneous including drug titration and patient 
populations. The major difference between our study and previously study is that we used arandomized controlled study. Our results show that the addition of dexmedetomidine to a TIVA regimen does not adversely affect the MEP and SSEP monitoring. In contrast, Mahmoud et al. reported two cases of loss of MEP amplitude during pediatric spine surgery with dexmedetomidine [15]. One case was an obese child, propofol and dexmedetomidine were calculated on actual rather than lean body mass. It is therefore possible that the patient had higher serum concentration of both drugs. In the second patient, decreased MEP amplitude was monitored after a bolus of $1 \mu \mathrm{g} / \mathrm{kg}$ dexmedetomidine was administered over $10 \mathrm{~min}$. It is possible that the combination of dexmedetomidine and propofol might have a cumulative suppressing effect on MEP. Our study included patients between 18 and 60 years old and the dose of dexmedetomidine we use that would approximate the plasma levels achieved by Bala et al. [10]. Even in DP unadjusted group, the deepening of anesthesia via propofol infusion does not necessarily affect the MEP and SSEP monitoring.

This study has limitations. First, a fixed dose of dexmedetomidine, which is $0.5 \mu \mathrm{g} / \mathrm{kg}$ loading dose for $10 \mathrm{~min}$ followed by a $0.5 \mu \mathrm{g} / \mathrm{kg} / \mathrm{h}$ infusion, didn't ensure a constant level of its plasma concentration. Second, we recruited patients scheduled for elective thoracic spinal cord tumor resection. Poor signal of MEP and SSEP is inavoidable in such patients. Malhotra [16] reported that ability to achieve intraoperative monitor baseline data varied from 70 to $98 \%$ for SSEP and 66 to $100 \%$ for MEP in absence of neural axis abnormality. In this study, the total excluded number in three groups are respectively $5 / 30,7 / 30,7 / 30$ respectively. Although the high percent of failure rate may lead to a selection bias, the remaining patients in each group are still comparable to study the effects of dexmedetomidine in a clinically relevant dose on MEP and SSEP.

\section{Conclusion}

The addition of dexmedetomidine in a commonly used clinical dose to a propofol-remifentanil regimen does not exert an adverse effect on MEP and SSEP monitoring in adult patients undergoing thoracic spinal cord tumor resection. In this patient population, dexmedetomidine could be added to the TIVA regimen without altering the propofol dose thereby deepening the anesthesia without adversely influencing MEP and SSEP monitoring.

\section{Abbreviations}

MEP: motor-evoked potentials; SSEP: somatosensory-evoked potentials; BIS: bispectral index; TIVA: total intravenous anesthesia; MRI: magnetic resonance imaging; ASA: American Society of Anesthesiologists; MAP: mean arterial pressure; HR: heart rate

\section{Acknowledgments}

We gratefully acknowledge Li Liu and Mingran Wang, for their helpful suggestions on the study and assistance with the motor- and somatosensoryevoked potential monitoring.

\section{Funding}

There was no funding for the research.

\section{Availability of data and materials}

The datasets during the current study are available from the corresponding author on reasonable request.

\section{Authors' contributions}

YL carried out the study and drafted the manuscript. LM helped to draft the manuscript and revise it critically for important intellectual content. YP performed the statistical analysis. HQ helped to carry out the study. LG participated in the design of the study. RH and AWG conceived of the study, and participated in its design and coordination and helped to draft the manuscript. All authors read and approved the final manuscript.

\section{Competing interests}

This study was conducted in and supported by Department of Anesthesiology, Beijing Tiantan Hospital, Capital Medical University. There was no competing interest.

\section{Consent for publication}

There was no individual person's data in the manuscript.

\section{Ethics approval and consent to participate}

The study was approved by the Ethics Committee of Beijing Tiantan Hospital, Capital Medical University (reference number was ky-2010-018-02). Written informed consent was obtained from all participants.

\section{Author details \\ ${ }^{1}$ Department of Anesthesiology, Beijing Tiantan Hospital, Capital Medical University, No. 6 Tiantan Xili Dongcheng District, Beijing, China 100050. ${ }^{2}$ Neurophysiological Monitoring, Beijing Tiantan Hospital, Capital Medical University, Beijing, China. ${ }^{3}$ Departments of Anesthesia and Perioperative Care, University of California San Francisco, San Francisco, CA, USA. ${ }^{4}$ Neurosurgery/ Neurophysiological Monitoring Service, University of California San Francisco, San Francisco, CA, USA.}

Received: 19 December 2015 Accepted: 21 July 2016

Published online: 02 August 2016

\section{References}

1. Chen Z. The effects of isoflurane and propofol on intraoperative neurophysiological monitoring during spinal surgery. J Clin Monit Comput. 2004;18(4):303-8.

2. Wang AC, Than KD, Etame AB, La Marca F, Park P. Impact of anesthesia on transcranial electric motor evoked potential monitoring during spine surgery: a review of the literature. Neurosurg Focus. 2009;27(4):E7.

3. Lotto ML, Banoub M, Schubert A. Effects of anesthetic agents and physiologic changes on intraoperative motor evoked potentials. J Neurosurg Anesthesiol. 2004;16(1):32-42.

4. Liu HY, Zeng HY, Cheng H, Wang MR, Qiao H, Han RQ. Comparison of the effects of etomidate and propofol combined with remifentanil and quided by comparable BIS on transcranial electrical motor-evoked potentials during spinal surgery. J Neurosurg Anesthesiol. 2012;24(2):133-8.

5. Scheufler KM, Reinacher PC, Blumrich W, Zentner J, Priebe HJ. The modifying effects of stimulation pattern and propofol plasma concentration on motor-evoked potentials. Anesth Analg. 2005;100(2):440-7.

6. Mariappan $\mathrm{R}$, Ashokkumar H, Kuppuswamy B. Comparing the effects of oral clonidine premedication with intraoperative dexmedetomidine infusion on anesthetic requirement and recovery from anesthesiain patients undergoing major spine surgery. J Neurosurg Anesthesiol. 2014;26(3):192-7.

7. Freeman KA, Fullerton DA, Foley LS, Bell MT, Cleveland Jr JC, Weyant MJ, et al. Spinal cord protection in alpha-2 agonist-mediated increase in glial cell-linederived neurotropic factor. J Thorac Cardiovasc Surg. 2015;149(2):578-86. 
8. Kuhmonen J, Pokorný J, Miettinen R, Haapalinna A, Jolkkonen J, Riekkinen Sr P, et al. Neuroprotective effects of dexmedetomidine in the gerbil hippocampus after transient global ischemia. Anesthesiology. 1997;87(2):371-7.

9. Maier C, Steinberg GK, Sun GH, Zhi GT, Maze M. Neuroprotection by the a2-adrenoreceptor agonist dexmedetomidine in a focal model of cerebral ischemia. Anesthesiology. 1993;79(2):306-12.

10. Bala E, Sessler D, Nair DR, McLain R, Dalton JE, Farag E. Motor and somatosensory evoked potentials are well maintained in patients given dexmedetomidine during spine surgery. Anesthesiology. 2008;109(3):417-25.

11. Mohamed M, Senthilkumar S, Shelia S, Nick TG, Schnell B, Sestokas AK, et al. Susceptibility of transcranial electric motor-evoked potentials to varying targeted blood levels of dexmedetomidine during spine surgery. Anesthesiology. 2010;112(6):1364-73.

12. Anschel DJ, Aherne A, Soto RG, Carrion W, Hoegerl C, Nori P, et al. Successful intraoperative spinal cord monitoring during scoliosis surgery using a total intravenous anesthetic regimen including dexmedetomidine. J Clin Neurophysiol. 2008;25(1):56-61.

13. Tobias JD, Goble TJ, Bates G, Anderson JT, Hoernschemeyer DG. Effects of dexmedetomidine on intraoperative motor and somatosensory evoked potential monitoring during spinal surgery in adolescents. Paediatr Anaesth. 2008;18(11):1082-8.

14. Rozet I, Metzner J, Brown M, Treggiari MM, Slimp JC, Kinney G, et al. Dexmedetomidine does not affect evoked potentials during spine surgery. Anesth Analg. 2015;121(2):492-501.

15. Mahmoud M, Sadhasivam S, Sestokas AK, Samuels P, McAuliffe J. Loss of transcranial electric motor evoked potentials during pediatric spine surgery with dexmedetomidine. Anesthesiology. 2007;106(2):393-6.

16. Malhotra NR, Shaffrey Cl. Intraoperative electrophysiological monitoring in spine surgery. Spine. 2010;35(25):2167-79.

17. Bell MT, Agoston VA, Freeman KA, Puskas F, Herson PS, Mares J, et al. Interruption of spinal cord microglial signaling by alpha-2 agonist dexmedetomidine in a murine model of delayed paraplegia. J Vasc Surg. 2014:59(4):1090-7.

18. Samra SK, Dy EA, Welch KB, Lovely LK, Graziano GP. Remifentanil-and fentanyl-based anesthesia for intraoperative monitoring of somatosensory evoked potentials. Anesth Analg. 2001;92(6):1510-5.

\section{Submit your next manuscript to BioMed Central and we will help you at every step:}

- We accept pre-submission inquiries

- Our selector tool helps you to find the most relevant journal

- We provide round the clock customer support

- Convenient online submission

- Thorough peer review

- Inclusion in PubMed and all major indexing services

- Maximum visibility for your research

Submit your manuscript at www biomedcentral.com/submit

) Biomed Central 